\title{
Delivery of Twin Gestation ( $\geq 32.0$ Weeks): The Vaginal Route as a Practicable and Safe Alternative to Cesarean Section
}

\author{
Entbindungsmodus bei Zwillingsschwangerschaft \\ ( $\geq 32,0$ Schwangerschaftswochen): die vaginale Route als \\ praktikable und sichere Alternative zur Kaiserschnittentbindung
}

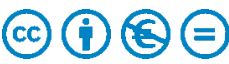

Authors

Anne Dathan-Stumpf ${ }^{1 *}$, Katharina Winkel ${ }^{2 *}$, Holger Stepan ${ }^{1}$

\author{
Affiliations \\ 1 University Hospital Leipzig, Department of Obstetrics, \\ Leipzig, Germany \\ 2 University Leipzig, Leipzig, Germany
}

Key words twin gestation, vaginal delivery, neonatal outcome, delivery mode

\section{Schlüsselwörter}

Zwillingsschwangerschaft, vaginale Entbindung, neonatales Outcome, Entbindungsmodus

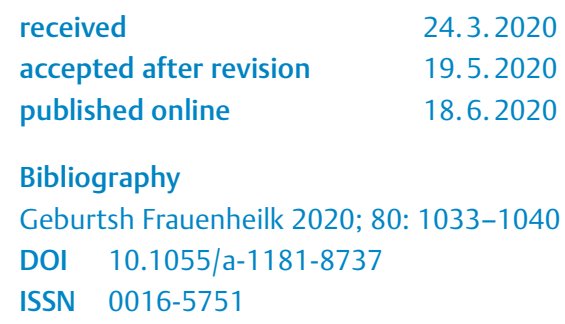
Attribution-NonDerivative-NonCommercial-License, permitting copying and reproduction so long as the original work is given appropriate credit. Contents may not be used for commercial purposes, or adapted, remixed, transformed or built upon. (https://creativecommons.org/licenses/by-nc-nd/4.0/)

Correspondence

Anne Dathan-Stumpf, MD

University Hospital Leipzig, Department of Obstetrics

Liebigstraße 20a, 04103 Leipzig, Germany

anne.dathan-stumpf@medizin.uni-leipzig.de

\section{ABSTRACT}

Objective The appropriate delivery mode for twins is discussed controversially in the literature. The aim of this study was to investigate delivery modes and short-term neonatal outcomes of twin pregnancies delivered in University Hospital Leipzig.

Material and Methods A total of 274 twin pregnancies (32.0 to 39.4 weeks of gestation) delivered between 2015 and 2017 were analyzed retrospectively with regard to the planned and final delivery mode as well as neonatal outcomes. The inclusion and exclusion criteria for vaginal delivery were comparable to those of the Twin Birth Study.

Results The spontaneous birth rate for births planned as vaginal deliveries was $78.5 \%$; the rate of secondary cesarean section was $19.4 \%$. The final total cesarean rate was $58.8 \%$, and the rate of vaginal deliveries was $41.2 \%$. Vertex or non-vertex position of the second twin had no significant effect on neonatal outcome or mean delivery interval between the birth of the first and second twin. Chorionicity, neonatal weight and gender had no significant impact on delivery mode. However, successful vaginal delivery was associated with higher gestational age and both fetuses in vertex position. The combined neonatal outcome for both twins was significantly worse if they were delivered by cesarean section compared to spontaneous birth. In addition, the leading twin in monochorionic/ diamniotic (MC/DA) pregnancies was intubated more frequently after cesarean delivery and had significantly lower Apgar scores.

Conclusion Vaginal delivery in twin pregnancies is a practicable and safe option in specific defined conditions and when the appropriate infrastructure and clinical experience is available.

\section{ZUSAMMENFASSUNG}

Zielsetzung Der richtige Entbindungsmodus bei Zwillingsschwangerschaften wird in der Literatur kontrovers diskutiert. Ziel dieser Studie war es, die Entbindungsmodi und das kurzfristige neonatale Outcome von Zwillingsschwangerschaften,

\footnotetext{
* Both authors contributed equally.
} 
die im Universitätskrankenhaus Leipzig zwischen 2015 und 2017 entbunden wurden, zu untersuchen.

Material und Methoden Die Daten von 274 Zwillingsschwangerschaften (32,0 bis 39,4 Schwangerschaftswochen) wurden retrospektiv analysiert im Hinblick auf den geplanten und den tatsächlich durchgeführten Entbindungsmodus sowie das neonatale Outcome. Die Einschluss- und Ausschlusskriterien für eine vaginale Entbindung waren mit denen der Twin Birth Study vergleichbar.

Ergebnisse Die Rate der Spontangeburten bei den geplanten vaginalen Entbindungen war 78,5\%; die Rate der sekundären Kaiserschnittsentbindungen betrug 19,4\%. Die endgültige Kaiserschnittsrate für das gesamte Kollektiv betrug $58,8 \%$, und die Rate der vaginalen Entbindungen 41,2\%. Ob der 2. Zwilling sich in der Hinterhauptslage befand oder nicht, hatte keine signifikanten Auswirkungen auf das neonatale Outcome oder den durchschnttlichen Zeitabstand zwischen der Geburt des 1. und 2. Zwillings. Chorionizität, Geburtsgewicht und Geschlecht hatten keine signifikanten Auswirkungen auf den Entbindungsmodus. Aber eine erfolgreiche vaginale Entbindung war mit einem höheren Schwangerschaftsalter sowie einer Hinterhauptslage beider Feten assoziiert. Das kombinierte neonatale Outcome für beide Zwillinge war deutlich schlechter, wenn beide per Kaiserschnitt entbunden wurden, verglichen mit einer Spontangeburt. Dazu kam noch, dass der führende Zwilling bei monochorionischen/ diamniotischen (MC/DA) Schwangerschaften nach einer Kaiserschnittentbindung häufiger intubiert werden musste und deutlich niedrigere Apgar-Werte hatte.

Schlussfolgerung Unter spezifischen vordefinierten Bedingungen und bei Vorhandensein der erforderlichen Infrastruktur und medizinischen Erfahrung stellt die vaginale Entbindung eine praktikable und sichere Option bei Zwillingsschwangerschaften dar.

$\begin{array}{ll}\text { Abbreviations } \\ \text { BMI } & \text { body mass index } \\ \text { Cl } & \text { confidence interval } \\ \text { DA } & \text { diamniotic } \\ \text { DC } & \text { dichorionic } \\ \text { GW } & \text { weeks of gestation } \\ \text { ICU } & \text { intensive care unit } \\ \text { JUMODA } & \text { JUmeaux MODe d'Accouchement study } \\ \text { MA } & \text { monoamniotic } \\ \text { MC } & \text { monochorionic } \\ \text { OR } & \text { odds ratio } \\ \text { TBS } & \text { Twin Birth Study }\end{array}$

\section{Introduction}

In the last three decades, the incidence of multiple pregnancies has risen to $3.7 \%$ in Germany [1]. This rise is attributed to an increasing use of reproductive medicine and increasing maternal age [2]. Twin pregnancies are associated with a number of risks, including pre-eclampsia, preterm birth and growth retardation. The optimal delivery mode with regard to both neonatal and maternal outcomes is still discussed controversially in the literature. Some large-scale studies support planned cesarean delivery to reduce neonatal morbidity and mortality $[3,4]$. The cesarean rates for twin gestations are reported to be as high as $75 \%$ worldwide [5]. In parallel to international developments [6], the cesarean delivery rates of twin pregnancies have increased dramatically in Germany, rising by more than $20 \%$ over the last thirty years. The lowest increase was reported for university hospitals with perinatal centers [7]. According to the Institute for Quality Assurance and Transparency in Health Care, the rate reported for Germany in 2016 was $74.9 \%$ [8].

The reasons for these high cesarean section rates include insufficient obstetrical expertise, the belief that delivery by cesarean section may prevent avoidable complications, medico-legal issues and a lack of medical resources and skills. Breech position of the second twin also appears to be one of the reasons given for planned cesarean section [9]. However, it has been observed that delivery of the second fetus presenting in breech position is not correlated with increased neonatal or maternal morbidity [10]. Instead, there are international randomized studies showing adverse neonatal and maternal outcomes following primary cesarean section $[5,11,12]$. Therefore, the aim of this retrospective study was to analyze delivery modes and neonatal outcomes of twin pregnancies delivered at University Hospital Leipzig.

\section{Materials and Methods}

\section{Study population}

A total of 274 twin pregnancies between 32.0 and 39.4 weeks of gestation (GW) born at University Hospital Leipzig between 2015 and 2017 were included. The data were analyzed retrospectively. The mean gestational age was $36.6 \mathrm{GW}$. Mean maternal age was 31.7 years, which is approximately two years older than the mean maternal age in the Federal Republic of Germany [13]. A total of $57.7 \%$ of mothers were primiparae. Monochorionic-monoamniotic twin pregnancies were excluded from vaginal delivery and were planned primarily as cesarean sections. Neonatal outcomes were documented in addition to the planned and performed delivery modes. The combined neonatal outcome took the 5-minute Apgar score, neonatal mortality up to seven days post partum, the intubation rate and transfer to the ICU ( $\geq 36$ weeks of gestation) into account.

Our criteria for vaginal delivery were comparable to those used in the Twin Birth Study (TBS): MC/DA or DC/DA with the leading fetus in the vertex position, estimated weight of both children between $1500-4000 \mathrm{~g}$ and gestational age $\geq 32.0 \mathrm{GW}$. The exclusion criteria were monoamniotic twins, severe intrauterine growth restriction, lethal fetal anomalies or contraindications to vaginal delivery (e.g., growth discordance $>20 \%$, vertical uterine incision in a previous cesarean section) [11]. 


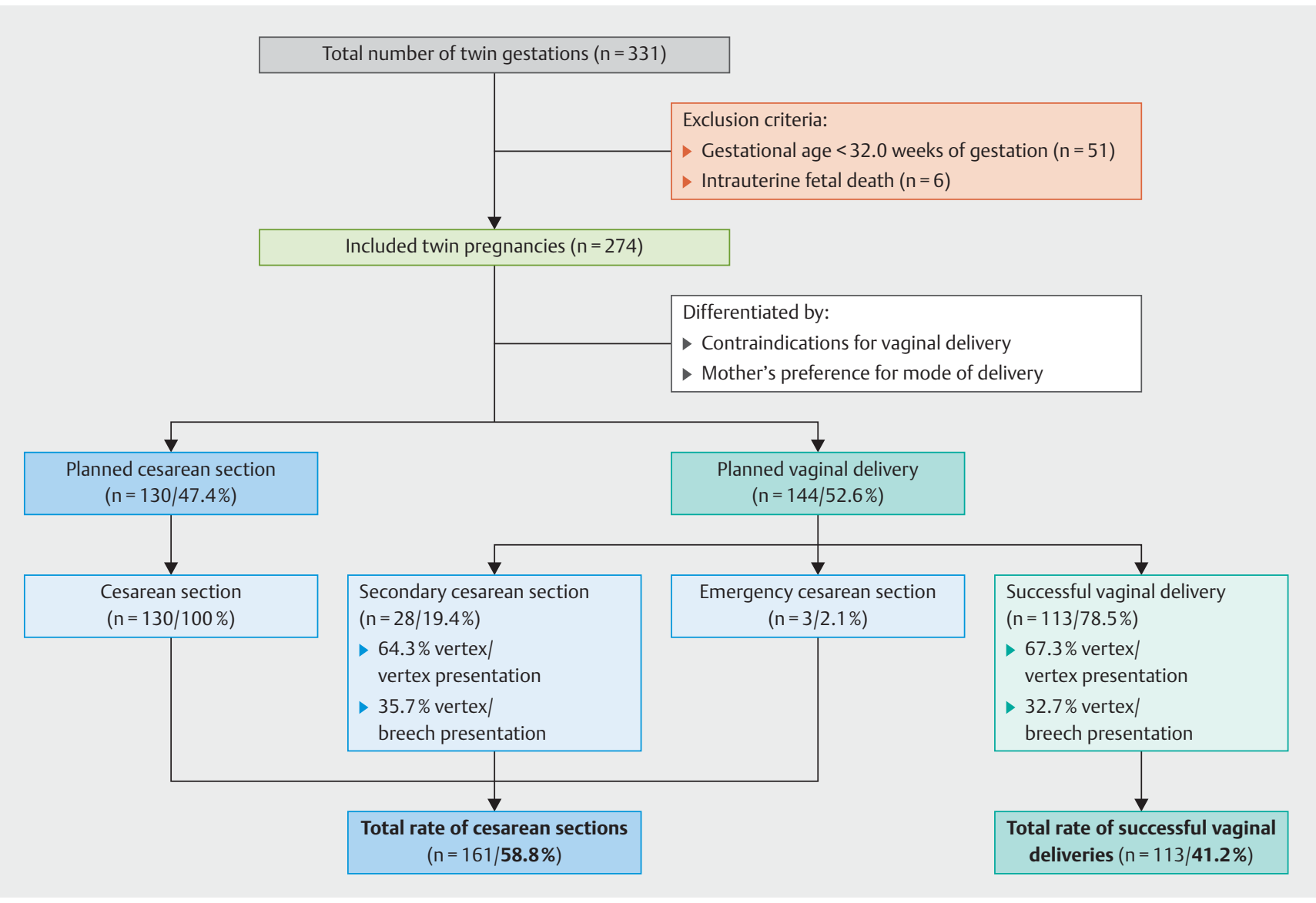

- Fig. 1 Presentation of the study collective with distribution of planned and performed delivery modes for twin gestations at University Hospital Leipzig from 2015 to 2017. The vaginal birth rate for births planned as spontaneous deliveries was $78.5 \%$ and the overall rate of vaginal deliveries was $41.2 \%$.

\section{Obstetric management of vaginal twin delivery in University Hospital Leipzig}

Vaginal twin delivery should be managed by a team consisting of a senior physician/experienced obstetrician with perinatal sub-specialization, an additional obstetrician, two midwives and a neonatologist. A cesarean section team must be on standby. After delivery of the first fetus, the patient's abdomen is externally stabilized to keep the second fetus in a longitudinal position and prevent it from shifting to a transverse position, irrespective of whether it is in a vertex or non-vertex position. If the second fetus is in a transverse position, this can be corrected by targeted external manipulation into a longitudinal position. If the second fetus shows rupture of membranes and is in a transverse position, a combination of internal and external version with extraction from the breech position is performed. Delivery of the second fetus is not forced as long as no CTG abnormalities or other obstetrical complications (increased bleeding, circulatory dysregulation of the mother) are observed.

\section{Statistical analysis}

Statistical evaluation was carried out using the IBM Statistical Package for the Social Sciences (IBM SPSS V. 24). Standard statistical methods were used. The significance level was $5 \%(\alpha=0.05)$ for all tests. Normally distributed mean values were compared using t-test. Non-normally distributed metric values and ordinal data were evaluated using Mann-Whitney U-test. We used Pearson's Chi-square test and Fisher's exact test to investigate the relationship between two variables. Logistic regression analysis was used for binary data comparisons.

\section{Ethics approval and patient consent}

Written informed consent for the scientific use of the anonymized data was obtained as a standard institutional procedure for each patient. All procedures were in accordance with the ethical standards of the responsible (institutional and national) committee on human experimentation and conformed to the Helsinki Declaration of 1975 (in its most recently amended version). The study was registered to the Institutional Ethical Committee of the University of Leipzig (IRB00001750; registration number: 334/19-ek).

\section{Results}

\section{Population characteristics}

Of the 274 twin gestations, 144 (52.6\%) were planned as spontaneous deliveries and 130 (47.4\%) were planned as primary cesar- 
- Table 1 Distribution of planned delivery modes during the study period.

\begin{tabular}{|c|c|c|c|}
\hline Criteria & $\begin{array}{l}\text { Planned vaginal delivery } \\
(n=144)(\%)\end{array}$ & $\begin{array}{l}\text { Planned cesarean section } \\
(n=130)(\%)\end{array}$ & p-value \\
\hline \multicolumn{4}{|l|}{ Presentation of the fetuses } \\
\hline - Vertex/vertex presentation & $95(66)$ & $44(33.8)$ & $<0.001$ \\
\hline - Vertex/breech presentation & $49(34)$ & $32(24.6)$ & 0.088 \\
\hline - Breech presentation of 1st fetus & 0 & $54(41.5)$ & $<0.001$ \\
\hline \multicolumn{4}{|l|}{ Chorionicity } \\
\hline - DC/DA & $117(81.3)$ & $98(75.4)$ & 0.238 \\
\hline - MC/DA & $27(18.8)$ & $26(20.0)$ & 0.794 \\
\hline - MC/MA & 0 & $6(4.6)$ & 0.011 \\
\hline Maternal age (years) & $31.4 \pm 4.6$ & $32 \pm 5.3$ & 0.277 \\
\hline Parity $\geq 1$ & $69(47.9)$ & $47(36.2)$ & 0.049 \\
\hline Body mass index $\left(\mathrm{kg} / \mathrm{m}^{2}\right)$ & $24.2 \pm 4.9$ & $24.2 \pm 5.5$ & 0.973 \\
\hline Gestational age (weeks) & $36.9 \pm 1.5$ & $36.2 \pm 1.8$ & 0.001 \\
\hline - 32.0 to $33.6 \mathrm{GW}$ & $7(4.9)$ & $16(12.3)$ & 0.026 \\
\hline - 34.0 to $36.6 \mathrm{GW}$ & $47(32.6)$ & $49(37.7)$ & 0.381 \\
\hline - 37.0 to $38.6 \mathrm{GW}$ & $88(61.1)$ & $65(50.0)$ & 0.064 \\
\hline . $\geq 39.0 \mathrm{GW}$ & $2(1.4)$ & 0 & 0.499 \\
\hline \multicolumn{4}{|l|}{ Estimated weight (g) } \\
\hline - 1st fetus & $2614.3 \pm 389.8$ & $2455.9 \pm 447.2$ & 0.002 \\
\hline - 2nd fetus & $2545.2 \pm 369.3$ & $2392.8 \pm 477.6$ & 0.004 \\
\hline
\end{tabular}

ean sections. The vaginal birth rate of the births intended to be spontaneous deliveries was $78.5 \%(n=113)$. The risk of secondary cesarean section was $19.4 \%(n=28)$, and the rate of cesarean section for the second twin was $2.1 \%(n=3)$. Thus, the total rate of cesarean sections was $58.8 \%(n=158)$, and the overall rate of vaginal deliveries was $41.2 \%$ ( $\vee$ Fig. 1). All twin gestations planned for delivery by cesarean section were performed as such. The distribution of chorionicity and fetal position are shown in $>$ Table 1. Vertex position of both fetuses was the main presentation in the planned spontaneous delivery group, while in the group with planned cesarean section, the leading fetus was more commonly in breech position. The gender distribution of the fetuses was comparable in both groups $(p=0.45)$. There were significant differences between the two planned delivery modes ( $>$ Table 1 ). In the group with the planned cesarean section, mean gestational age and mean estimated weight were lower. Multiparous women were planned more frequently for spontaneous delivery. BMI and maternal age did not significantly affect the choice of delivery mode ( $\vee$ Table 1$)$.

More than $25 \%$ of twin gestations (26.3\%) resulted from reproductive medical interventions: $61.1 \%$ from intracytoplasmic sperm injection, $37.5 \%$ from in vitro fertilization, and $1.4 \%$ from intrauterine insemination. There was no significant correlation between the use of reproductive medical interventions and the planned delivery mode.

\section{Delivery mode}

When secondary cesarean section was compared with successful vaginal delivery, no significant differences were found in terms of gestational age, chorionicity, birth weight or position of the second twin ( $p=0.77$ ). The main causes for secondary cesarean section were obstructed delivery at the expulsion stage (32.1\%), opening period (25\%), pathological CTG (17.8\%), unsuccessful induction of labor (10.7\%) and a change in the position of the leading fetus (10.7\%). Maternal age, BMI or the use of reproductive medical interventions did not have a significant effect on secondary cesarean section. However, mothers who had secondary cesarean were significantly more often primiparae (89.3 vs. 43.4\%, OR 11.09, 95\% Cl (Cl = confidence interval): 3.19-40.21, $\mathrm{p}<0.001)$ ( $>$ Table 2).

Emergency section to deliver the second fetus was performed in three cases (2.1\%). The main reason for delivering the second twin by cesarean section was CTG abnormalities. Statistical significance analysis was not carried out, due to the small number of cases with combined delivery modes.

Operative vaginal delivery was performed in 12 cases, with vacuum extraction preferred to forceps delivery (91.7 vs. 8.3\%). Operative vaginal delivery was performed five times for the first twin, four times for the second twin, and three times for both infants. 
- Table 2 Distribution for delivery modes according to presentation of fetuses, chorionicity, gestational age and other characteristics with respective p-values.

\begin{tabular}{|c|c|c|c|c|}
\hline Criteria & $\begin{array}{l}\text { Vaginal delivery } \\
(\mathrm{n}=113)(\%)\end{array}$ & $\begin{array}{l}\text { Secondary cesarean } \\
\text { section }(n=28)(\%)\end{array}$ & $\begin{array}{l}\text { Cesarean section } \\
(\mathrm{n}=158)(\%)\end{array}$ & $\mathbf{p}^{*} / \mathbf{p}^{* *}$-values \\
\hline \multicolumn{5}{|l|}{ Presentation of the fetuses } \\
\hline - Vertex/vertex presentation & $76(67.3)$ & $18(64.3)$ & $62(39.2)$ & $0.77 \mid<0.001$ \\
\hline - Vertex/breech presentation & $37(32.7)$ & $10(35.7)$ & $42(26.6)$ & $0.77 / 0.27$ \\
\hline - Breech presentation of 1 st fetus & 0 & 0 & $54(34.2)$ & $\mid<0.001$ \\
\hline \multicolumn{5}{|l|}{ Chorionicity } \\
\hline - DC/DA & $91(80.5)$ & $24(85.7)$ & $122(77.2)$ & $0.53 / 0.51$ \\
\hline - MC/DA & $22(19.5)$ & $4(14.3)$ & $30(19.0)$ & $0.53 / 0.92$ \\
\hline - MC/MA & 0 & 0 & $6(3.8)$ & 10.04 \\
\hline Gestational age & $36.9 \pm 1.5$ & $37.1 \pm 1.5$ & $36.4 \pm 1.8$ & $0.28 / 0.01$ \\
\hline . 32.0 to $33.6 \mathrm{GW}$ & $6(5.3)$ & $1(3.6)$ & $17(10.8)$ & $0.99 / 0.11$ \\
\hline - 34.0 to $36.6 \mathrm{GW}$ & $38(33.6)$ & $8(28.6)$ & $57(36.1)$ & $0.61 / 0.68$ \\
\hline - 37.0 to $38.6 \mathrm{GW}$ & $67(59.3)$ & $19(67.9)$ & $84(53.2)$ & $0.41 / 0.32$ \\
\hline - $\geq 39.0 \mathrm{GW}$ & $2(1.8)$ & 0 & 0 & $0.99 / 0.17$ \\
\hline Maternal age (years) & $31.4 \pm 4.7$ & $30.9 \pm 4.1$ & $31.8 \pm 5.1$ & $0.61 / 0.47$ \\
\hline Parity $\geq 1$ & $64(56.6)$ & $3(10.7)$ & $50(31.6)$ & $<0.001 /<0.001$ \\
\hline Body mass index $\left(\mathrm{kg} / \mathrm{m}^{2}\right)$ & $24.1 \pm 4.7$ & $24.8 \pm 5.9$ & $24.3 \pm 5.5$ & $0.61 / 0.82$ \\
\hline $\begin{array}{l}\text { Mean interval between delivery } \\
\text { of } 1 \mathrm{st} / 2 \mathrm{nd} \text { twin ( } \mathrm{min})\end{array}$ & $6.7 \pm 4$ & & $1.5 \pm 0.8$ & $<0.001$ \\
\hline \multicolumn{5}{|l|}{ Birth weight $(g)$} \\
\hline - 1st twin & $2588.1 \pm 381.6$ & $2708.2 \pm 422.3$ & $2500.6 \pm 452.1$ & $0.18 / 0.09$ \\
\hline - 2nd twin & $2502.9 \pm 344.3$ & $2669.8 \pm 435.1$ & $2441.9 \pm 480.9$ & $0.07 / 0.23$ \\
\hline \multicolumn{5}{|c|}{$\mathrm{p}^{*}$-value: $\mathrm{p}$-value for vaginal delivery and secondary cesarean section } \\
\hline \multicolumn{5}{|c|}{$\mathrm{p}^{* *}$-value: $\mathrm{p}$-value for vaginal delivery and cesarean section (total) } \\
\hline \multicolumn{5}{|c|}{$\begin{array}{l}\text { Significant findings }(\mathrm{p}<0.05) \text { are highlighted in bold. Presentation of the second fetus and chorionicity were not significant for the individual delivery } \\
\text { modes. }\end{array}$} \\
\hline
\end{tabular}

\section{Position of the second fetus}

In successful vaginal delivery, the second twin was in the vertex position in $67.3 \%(n=76)$ of cases and in breech presentation in $32.7 \%(n=37)$. Presentation of the second twin had no significant effect on the combined neonatal outcome $(p=0.54)$ or individual variables. Moreover, the $\mathrm{pH}$ value was not found to be significantly different (vertex $\mathrm{pH}$ value $7.25 \pm 0.1$ vs. non-vertex $\mathrm{pH}$ value $7.23 \pm 0.08, p=0.32$ ). The mean interval between delivery of the first and the second twin was not affected by the position of the second twin ( $p=0.12)$.

Comparison of vaginal delivery with cesarean section showed that mothers who had a successful vaginal delivery were significantly more likely to be multiparous, while women who had a cesarean section were often primiparae $(p<0.001)$. No significant differences between the two delivery modes were found with regard to chorionicity, birth weight or gender ( $>$ Table 2). However, successful vaginal delivery was associated with higher gestational age. Additionally, the interval between the birth of the first and second twin differed significantly $(p<0.001)$. Specifically, the mean value of the interval was $6.7 \pm 4$ minutes for vaginal delivery and $1.5 \pm 0.8$ minutes for cesarean section ( $\triangleright$ Table 2 ).

\section{Short-term neonatal outcome}

Surprisingly, the combined short-term neonatal outcome of both fetuses in the cesarean section group was significantly worse than that of neonates in the successful spontaneous delivery group $(p=0.012$ ), although no significant differences in individual factors were observed for combined neonatal outcomes. For example, it was more common after cesarean section that the first twin required intubation and treatment in the ICU ( $\vee$ Table 3 ). As expected, the $\mathrm{pH}$ values of both twins in the group with cesarean sections were higher $(p<0.001)$.

\section{Chorionicity}

Chorionicity had no significant impact on rates of cesarean sections (DC/DA 57.3\% vs. MC/DA 57.7\%), combined neonatal outcomes and delivery-related $\mathrm{pH}$ values of all fetuses. MC/DA twins were more frequently transferred to the ICU after delivery, but this difference was not significant. However, in MC/DA twins, the leading fetus had to be intubated more frequently after cesarean section, had lower Apgar scores and a worse combined neonatal outcome ( $\triangleright$ Table 4). 
- Table 3 Short-term neonatal outcomes for the different delivery modes.

\begin{tabular}{|c|c|c|c|}
\hline Neonatal outcome & Vaginal delivery $(n=113)(\%)$ & Cesarean section $(n=158)(\%)$ & p-value \\
\hline \multicolumn{4}{|c|}{ Apgar score (at 5 minutes) $<7$} \\
\hline - 1st twin & $2(1.8)$ & $6(3.8)$ & 0.48 \\
\hline - 2nd twin & $4(3.5)$ & $9(5.7)$ & 0.41 \\
\hline \multicolumn{4}{|l|}{ Intubation required } \\
\hline - 1st twin & $2(1.8)$ & $10(6.3)$ & 0.07 \\
\hline - 2nd twin & $5(4.4)$ & $10(6.3)$ & 0.50 \\
\hline \multicolumn{4}{|c|}{ Transfer to ICU ( $\geq 36.0$ weeks of gestation) } \\
\hline - 1st twin & $6(5.3)$ & $15(9.5)$ & 0.20 \\
\hline - 2nd twin & $12(10.6)$ & $18(11.4)$ & 0.84 \\
\hline \multicolumn{4}{|c|}{ Combined neonatal outcome } \\
\hline - 1st twin & $8(7.1)$ & $24(15.2)$ & 0.04 \\
\hline . 2nd twin & $14(12.4)$ & $29(18.4)$ & 0.19 \\
\hline - both & 22 & 56 & 0.01 \\
\hline \multicolumn{4}{|l|}{$\mathrm{pH}$-value $<7.2$} \\
\hline - 1st twin & $14(12.4)$ & 0 & $<0.001$ \\
\hline - 2nd twin & $33(29.2)$ & $6(3.8)$ & $<0.001$ \\
\hline
\end{tabular}

The combined neonatal outcome took the 5-minute Apgar score, neonatal mortality up to seven days post partum, intubation rates and transfers to the ICU into account. Significant findings $(\mathrm{p}<0.05)$ are highlighted in bold. Newborns delivered by cesarean section had significantly better $\mathrm{pH}$ values but also significantly worse combined neonatal outcomes.

- Table 4 Neonatal outcomes for the delivery modes 'vaginal birth' $(n=113)$ and 'cesarean section' $(n=152)$, and distribution of chorionicity (with the exception of MC/MA gestations [ $n=6]$ ).

\begin{tabular}{|c|c|c|c|c|c|c|}
\hline \multirow[t]{2}{*}{ Neonatal outcome } & \multicolumn{3}{|c|}{ Vaginal delivery $(n=113)$} & \multicolumn{3}{|c|}{ Cesarean section $(n=152)$} \\
\hline & $\begin{array}{l}\text { MC/DA } \\
(n=22)(\%)\end{array}$ & $\begin{array}{l}\text { DC/DA } \\
(n=91)(\%)\end{array}$ & p-value & $\begin{array}{l}M C / D A \\
(n=30)(\%)\end{array}$ & $\begin{array}{l}\text { DC/DA } \\
(n=122)(\%)\end{array}$ & p-value \\
\hline \multicolumn{7}{|c|}{ Apgar score (at 5 minutes) < 7} \\
\hline - 1st twin & $1(4.5)$ & $1(1.1)$ & 0.35 & $4(13.3)$ & $2(1.6)$ & 0.01 \\
\hline - 2nd twin & $1(4.5)$ & $3(3.3)$ & 1.0 & $2(6.7)$ & $6(4.9)$ & 1.0 \\
\hline \multicolumn{7}{|l|}{ Intubation required } \\
\hline - 1st twin & $1(4.5)$ & $1(1.1)$ & 0.35 & $5(16.7)$ & $3(2.5)$ & 0.008 \\
\hline - 2nd twin & $1(4.5)$ & $4(4.4)$ & 1.0 & $3(10.0)$ & $6(4.9)$ & 0.38 \\
\hline \multicolumn{7}{|c|}{$\begin{array}{l}\text { Transfer to ICU } \\
\text { ( } \geq 36.0 \text { weeks of gestation) }\end{array}$} \\
\hline - 1st twin & $2(9.1)$ & $4(4.4)$ & 0.60 & $4(13.3)$ & $11(9.0)$ & 0.50 \\
\hline - 2nd twin & $4(18.2)$ & $8(8.8)$ & 0.25 & $4(13.3)$ & $14(11.5)$ & 1.0 \\
\hline \multicolumn{7}{|c|}{ Combined neonatal outcome } \\
\hline - 1st twin & $3(13.6)$ & $5(5.5)$ & 0.35 & $8(26.7)$ & $14(11.5)$ & 0.04 \\
\hline - 2nd twin & $4(18.2)$ & $10(11.0)$ & 0.47 & $6(20.0)$ & $21(17.2)$ & 0.72 \\
\hline - both & $7(15.9)$ & $15(8.2)$ & 0.15 & $14(23.3)$ & $35(14.3)$ & 0.09 \\
\hline \multicolumn{7}{|l|}{$\mathrm{pH}$ value $<7.2$} \\
\hline - 1st twin & $1(4.5)$ & $13(14.3)$ & 0.30 & 0 & 0 & 1.0 \\
\hline - 2nd twin & $7(31.8)$ & $26(28.6)$ & 0.76 & 0 & $6(5.0)$ & 0.35 \\
\hline
\end{tabular}

The combined neonatal outcome took the 5-minute Apgar score, neonatal mortality up to 7 days post partum, intubation rates and transfers to the ICU into account. Significant findings $(p<0.05)$ are highlighted in bold. The neonatal outcome of leading MC/DA fetuses delivered by cesarean section was poor in many respects. 


\section{Discussion}

The appropriate delivery mode for twins is still an internationally discussed and investigated topic. There are only a few German studies on twin births. This is an issue that needs to be discussed more widely across the obstetric community, as cesarean rates for twins are still very high. High cesarean section rates when delivering twins are not supported by the data or the literature. However, hospitals with limited medical resources and skills often choose cesarean section as the primary mode of delivery to avoid potential complications. Cesarean sections are associated with a number of complications, including increased blood loss, increased risk of placental disorders [14], subsequent uterine rupture [15] and neonatal adaptation disorders [16]. At University Hospital Leipzig, spontaneous delivery is preferred in the absence of contraindications. Our aim is to decrease the rate of cesarean sections and to critically question the indications for cesarean section. From 2015 to 2017, the mean rate of delivery by cesarean section at University Hospital Leipzig, a first-level perinatal care center, was $25.0 \%$. The average rate for deliveries by cesarean section in the Federal Republic of Germany was significantly higher at $30.7 \%$ [17]. The distributions were similar for twin pregnancies. The inclusion and exclusion criteria for vaginal delivery in our study were based on those of the TBS. In our study, the successful spontaneous delivery rate for twin births planned for vaginal delivery was $78.5 \%$. Thus, our success rates were significantly higher than those reported in the TBS (56.2\%) [11]. Both studies had comparable ratios for the two planned modes of delivery. The rate of vaginal deliveries in the prospective French cohort study JUMODA was $80.3 \%$, of which $75 \%$ were planned as spontaneous deliveries [5]. The results for secondary cesarean section and for cesarean delivery of the second fetus in our study were comparable to those of the other two studies. In contrast to the TBS and JUMODA studies, all twin gestations planned for cesarean delivery in our study were delivered by cesarean section.

The results of our study show that vaginal delivery of twin gestations aged $\geq 32.0 \mathrm{GW}$ with the leading fetus in the vertex position does not result in increased neonatal morbidity or mortality, irrespective of the presentation of the second twin [18]. Other studies have already reported that the position of the second fetus does not significantly affect the final delivery mode or the neonatal outcome [19-21]. However, our study showed a significant adverse short-term neonatal outcome after cesarean delivery. This trend was mediated by monochorionicity: compared to dichorionic gestations, the leading MC/DA fetuses had significantly lower Apgar scores and higher intubation rates. Overall, $47 \%$ of twins delivered by cesarean section were born at $<37.0 \mathrm{GW}$, compared to $39 \%$ aged $<37.0 \mathrm{GW}$ who were born spontaneously. This $8 \%$ difference for premature twins may explain the better short-term combined outcomes after vaginal delivery, although no significant differences were observed with respect to individual factors. Nevertheless, adverse neonatal outcomes after primary cesarean section have also been reported in other studies [5, 22], often due to respiratory distress [23]. The study of mature twins by Ylilehto et al. (who reported a vaginal birth rate of $80.8 \%$ ) showed significantly lower 5-minute Apgar scores and an umbilical artery $\mathrm{pH}<7.05$ after vaginal delivery, irrespective of chorionicity.
Nevertheless, the authors reported that serious neonatal morbidity was rare and did not differ from that after planned cesarean section [24].

One possible limitation of our study is that data were analyzed retrospectively, while JUMODA and the Twin Birth Study were designed prospectively. In addition, significantly fewer pregnancies were included, as data were only collected from a single center. Despite the significantly lower numbers of cases, our results were similar to those shown in the international, randomized TBS and JUMODA study. With a total cesarean delivery rate of $58.8 \%$, the cesarean section rate in our study was significantly lower than the national average of $75 \%$ for multiple gestations [8].

In most studies of vaginal deliveries of twins, a gestational age $\geq 32.0$ weeks is assumed, with the intention of preventing intraventricular hemorrhages [25]. However, studies have found that the mode of delivery (vaginal vs. cesarean section) did not result in any significant difference in neonatal outcomes for extremely preterm twins delivered from the 24th week of gestation [26]. Based on the results of Barrett et al., vaginal delivery of twins will only be planned from 32.0 weeks of gestation, as is done in University Hospital Leipzig [11]. A large-scale randomized study should be considered to study the safety of vaginal delivery before the $32 \mathrm{nd}$ week of gestation as an equivalent alternative to primary cesarean section. This could further reduce the rate of cesarean sections and the associated complications.

The results presented here highlight the maternal and neonatal benefits of spontaneous birth. As other randomized multicenter studies have shown, planned vaginal delivery of twins is not associated with more negative primary outcomes in terms of fetal morbidity, neonatal death or adverse maternal effects $[27,28]$. According to another study, there was no significant difference with regard to the secondary neonatal outcome of death or neurodevelopmental delay 2 years later for twins born by uncomplicated vaginal delivery [29]. The vaginal route should be offered in the absence of clear medical contraindications [28], and obstetricians in perinatal centers should be trained to manage such situations. Increasing numbers of vaginal twin deliveries will expand the experience and increase the confidence of medical staff. Clinical expertise, careful delivery planning and provider selection are crucial to successful vaginal delivery [10].

\section{Conclusion}

From the 32nd week of gestation, the vaginal delivery of twins with the leading twin in the vertex position is a viable alternative with no adverse neonatal outcomes. The position of the second fetus is irrelevant with respect to the outcome. However, the clinical experience of the obstetrician and the availability of appropriate resources are crucial. Therefore, delivery of twin gestations should be reserved for centers of maximum care which have the appropriate expertise and infrastructure. 


\section{Declarations}

\section{Authors' contributions}

KW retrospectively collected and analyzed the data. ADS summarized the results into tables, interpreted the data and was the major contributor to the writing of the manuscript. HS planned the clinical study as well as writing and editing the manuscript. All authors read and approved the manuscript.

\section{Conflict of Interest}

The authors declare that they have no conflict of interest.

\section{References}

[1] Institut für Qualitätssicherung und Transparenz im Gesundheitswesen. Bundesauswertung zum Erfassungsjahr 2017 Geburtshilfe. 2018. Online: https://iqtig.org/downloads/auswertung/2017/16n1gebh/ QSKH_16n1-GEBH_2017_BUAW_V02_2018-08-01.pdf; last access: 01.08.2018

[2] Grubinger E, Scheier M. Mehrlingsschwangerschaften - Epidemiologie, Entwicklung und Morbidität. J Gynäkol Endokrinol 2011; 21: 14-19

[3] Hoffmann E, Oldenburg A, Rode L et al. Twin births: cesarean section or vaginal delivery? Acta Obstet Gynecol Scand 2012; 91: 463-469

[4] Roberts CL, Algert CS, Nippita TA et al. Association of prelabor cesarean delivery with reduced mortality in twins born near term. Obstet Gynecol 2015; 125: 103-110

[5] Schmitz T, Prunet C, Azria E et al. Association Between Planned Cesarean Delivery and Neonatal Mortality and Morbidity in Twin Pregnancies. Obstet Gynecol 2017; 129: 986-995

[6] Lee HC, Gould JB, Boscardin W] et al. Trends in cesarean delivery for twin births in the United States: 1995-2008. Obstet Gynecol 2011; 118: 1095-1101

[7] Kyvernitakis A, Kyvernitakis I, Karageorgiadis AS et al. Rising cesarean rates of twin deliveries in Germany from 1990 to 2012. Z Geburtshilfe Neonatol 2013; 217: 177-182

[8] Institut für Qualitätssicherung und Transparenz im Gesundheitswesen. Bundesauswertung zum Erfassungsjahr 2017 Geburtshilfe. 2018. Online: https://iqtig.org/downloads/auswertung/2017/16n1gebh/ QSKH_16n1-GEBH_2017_BUAW_V02_2018-08-01.pdf; last access: 01.08.2018

[9] Vogel JP, Holloway E, Cuesta C et al. Outcomes of non-vertex second twins, following vertex vaginal delivery of first twin: a secondary analysis of the WHO Global Survey on maternal and perinatal health. BMC Pregnancy Childbirth 2014; 14: 55

[10] Easter SR, Lieberman E, Carusi D. Fetal presentation and successful twin vaginal delivery. Am J Obstet Gynecol 2016; 214: 116.e1-116.e10

[11] Barrett JFR, Hannah ME, Hutton EK et al. A Randomized Trial of Planned Cesarean or Vaginal Delivery for Twin Pregnancy. N Engl J Med 2013; 369: $1295-1305$
[12] Korb D, Deneux-Tharaux C, Seco A et al. Risk of Severe Acute Maternal Morbidity According to Planned Mode of Delivery in Twin Pregnancies. Obstet Gynecol 2018; 132: 647-655

[13] DESTATIS - Statistisches Bundesamt. Durchschnittliches Alter der Mutter bei der Geburt des Kindes 2017 (biologische Geburtenfolge). 2017. Online: https://www.destatis.de/DE/Themen/GesellschaftUmwelt/Bevoelkerung/Geburten/Tabellen/geburten-mutter-alterbundeslaender.html; last access: 17.10.2016

[14] Dathan-Stumpf A, Faber R, Stepan H. Abnorm invasive Plazenta: klinisches Management. Frauenarzt 2018; 59: 674-677

[15] Vääräsmäki M, Raudaskoski T. Pregnancy and delivery after a cesarean section. Duodecim 2017; 133: 345-352

[16] Dunne C, Da Silva O, Schmidt G et al. Outcomes of elective labour induction and elective caesarean section in low-risk pregnancies between 37 and 41 weeks' gestation. J Obstet Gynaecol Can 2009; 31: 1124-1130

[17] DESTATIS - Statistisches Bundesamt. 30,5\% der Krankenhausentbindungen per Kaiserschnitt im Jahr 2017. 2018. Online: https://www.destatis. de/DE/PresseService/Presse/Pressemitteilungen/2018/09/PD18_349_ 231.html; last access: 17.09.2018

[18] Bibbo C, Robinson JN. Management of twins: vaginal or cesarean delivery? Clin Obstet Gynecol 2015; 58: 294-308

[19] Rossi AC, Mullin PM, Chmait RH. Neonatal outcomes of twins according to birth order, presentation and mode of delivery: a systematic review and meta-analysis. BJOG 2011; 118: 523-532

[20] Bogner G, Wallner V, Fazelnia C et al. Delivery of the second twin: influence of presentation on neonatal outcome, a case controlled study. BMC Pregnancy Childbirth 2018; 18: 176

[21] Schmitz T, Korb D, Battie $C$ et al. Neonatal morbidity associated with vaginal delivery of noncephalic second twins. Am J Obstet Gynecol 2018; 218: 449.e1-449.e13

[22] Pestana I, Loureiro T, Almeida A et al. Effect of mode of delivery on neonatal outcome of monochorionic diamniotic twin pregnancies: a retrospective cohort study. | Reprod Med 2013; 58: 15-18

[23] Hansen AK, Wisborg K, Uldbjerg $\mathrm{N}$ et al. Risk of respiratory morbidity in term infants delivered by elective caesarean section: cohort study. BM] 2008; 7635: 85-87

[24] Ylilehto E, Palomäki O, Huhtala $\mathrm{H}$ et al. Term twin birth - impact of mode of delivery on outcome. Acta Obstet Gynecol Scand 2017; 96: 589-596

[25] Barzilay E, Mazaki-Tovi S, Amikam U et al. Mode of delivery of twin gestation with very low birthweight: is vaginal delivery safe? Am J Obstet Gynecol 2015; 213: 219.e1-219.e8

[26] Dagenais C, Lewis-Mikhael AM, Grabovac M et al. What is the safest mode of delivery for extremely preterm cephalic/non-cephalic twin pairs? A systematic review and meta-analyses. BMC Pregnancy Childbirth 2017; 17: 397

[27] Mei-Dan E, Dougan C, Melamed N et al. Planned cesarean or vaginal delivery for women in spontaneous labor with a twin pregnancy: A secondary analysis of the Twin Birth Study. Birth 2019; 46: 193-200

[28] Lee HC, Blumenfeld Y]. Caesarean delivery for twin gestation at 32-38 weeks does not lead to improved clinical outcomes for neonates or mothers. Evid Based Med 2014; 19: 119

[29] Asztalos EV, Hannah ME, Hutton EK et al. Twin Birth Study: 2-year neurodevelopmental follow-up of the randomized trial of planned cesarean or planned vaginal delivery for twin pregnancy. Am J Obstet Gynecol 2016; 214: $371 . e 1-371 . e 19$ 